\title{
The comparative study of quality of life among working women and homemakers taking care of psychiatric patients presenting in a tertiary care hospital, Patna
}

\author{
Vivek Pratap Singh ${ }^{1}$, Alka Puria ${ }^{2}$, Abhishek Pratap Singh ${ }^{3}$, Narendra Pratap Singh ${ }^{4}$, \\ Ekram Goyal ${ }^{5}$
}

${ }^{1}$ Senior Resident, ${ }^{4}$ Professor and Head, Department of Psychiatry, Patna Medical College and Hospital, Patna, ${ }^{2} J u n i o r$ Resident, Department of Biochemistry, Darbhanga Medical College and Hospital, Darbhanga, ${ }^{3} J u n i o r$ Resident, Department of Medicine, Patna Medical College and Hospital, Patna, Bihar, ${ }^{5}$ Senior Resident, Department of Psychiatry, Government Medical College and Rajinder Hospital, Patiala, Punjab, India

A B S T R A C T

Background: In India, women are twice more likely to become caregivers than men. The quality of life (OOL) is the ability level to which an individual is healthy and able to enjoy life. Aims and Objective: To assess and compare QOL among homemaker women and working women giving care to patients suffering from psychiatric illnesses. Materials and Methods: This hospital-based, cross-sectional study was conducted on the caregivers who were recruited from out-door patient department of Psychiatry department of Patna Medical College and Hospital, Patna from January 1, 2021, to June 31, 2021. Women who were 30-55 years old, working or homemakers, and who were taking care of psychiatric patients diagnosed with Schizophrenia and Bipolar affective disorder of either sex. Caregivers were first degree relatives of patients. The estimated sample size was 140 (Group $1=70$ homemaker women and Group $2=70$ working women). Sociodemographic data were recorded using Sociodemographic Performa 1 and $\mathrm{OOL}$ was assessed using World Health Organization (WHO)-QoL-BREF. Results: WHO-QOL domain mean score for physical, psychological, social, and environmental of Group 1 was 12.42, 11.60, 12.24, 12.62 whereas $14.46,13.28,11.28$, and 12.28 of Group 2 with statistically significant difference $(\mathrm{P}<0.05)$. Conclusion: In physical and psychological domain of $\mathrm{QoL}$, working women scores were better than homemakers. QOL in working women caregivers was better than homemakers' caregivers in social and environmental domains but statistically non-significant.

Key words: Quality of life index; Caregiver; World Health Organization-quality of lifeBREF; Working women; Homemaker

\section{INTRODUCTION}

In India, the role of the family has been vital in taking care of persons suffering from severe mental disorder. It includes supervising medications, arranging for follow-up, bringing the patient for inpatient care, staying with the patient, and providing financial support. ${ }^{1}$
According to a latest survey, every sixth Indian requires mental health help and it's more in 30-49 years of age group or above 60; among low-income strata and urban areas. The prevalence of psychiatric disorder according to gender has been found almost similar between lifetime. In male it is $1.5 \%$ and in females, it stands to be around $1.3 \% 0^{2,3}$ 
Care-giver is defined as any person including parents and other family members who with or without payment provides care, support, or assistance to a person with a disability. ${ }^{3}$ Caregiver is a relative who stays with the patient, involved in looking after patient's daily needs, supervising medication, and accompanies him/her to the hospital. ${ }^{4}$ All over the world, women are the predominant providers of informal care for family members with mental illness; and they may be working women or homemakers. ${ }^{5}$ Working women earn the salary or wages through regular employment outside the home and easily juggle their career with raising children and taking care of various domestic chores. ${ }^{6}$ Homemakers, besides managing the household chores also take care of the sick and elderly. ${ }^{7}$ With the advancement of treatment modalities for the management of psychiatric patients, there is an increase in trend toward home-based treatment. ${ }^{8}$ The tendency of caregiver is to get an early discharge of mentally ill patients even if they need hospitalization for acute illness and treat them at home.

In India, women are twice more likely to become caregivers than men. Despite emergence of men as caregivers, researchers have not taken into account this trend and continue to maintain its traditional focus on female caregivers..$^{10}$ Yee and Schulz examined gender differences on caregiving had found women to spend more time on caregiving than men, which interfered with their work and social life to a greater extent. ${ }^{11}$

Stress is known as body reaction to any challenge and demand. ${ }^{12}$ Hans Selye has described three stages that the body utilizes to react to any stressors called General Adaptation Syndrome (GAS). They are three stages of GAS: First Stage: Alarm stage which provides burst of energy. Second stage: Known as resistance stage the body utilizes to resist or adapt to the stresses. Third stage: Known as the exhaustion stage because energy is depleted. ${ }^{13}$ There are external and internal factors for stress. External stress comes from outside: Our physical environment, relationship with others, job, etc., and internal stress comes from within, which determine our body's ability to respond and deal with stress. ${ }^{14}$

The quality of life (QOL) has been defined by World Health Organization (WHO) as an perception of an individual's about their position in life related to content of their value system and culture in which they live and its relation to their goals, expectations, standards, and concerns. ${ }^{15}$ The QOL is better in working women as mostly working women don't abandon their caregiving responsibilities because of employment instead they cope to the best of their abilities with the combined pressures of caring for a loved one the toll that caregiving takes is not financial. ${ }^{16}$

Hence, the present study is aimed at assessing and comparing QOL among working women and homemaker women taking care of patients diagnosed with schizophrenia and bipolar affective disorder (BAPD).

\section{Aims and Objectives}

To assess and compare quality of life among working women and homemaker women taking care of patients diagnosed with schizophrenia and bipolar affective disorder.

\section{MATERIALS AND METHODS}

This was a hospital based, cross-sectional study. The caregivers were recruited from out-door patient department (OPD) of Psychiatry of Patna Medical College and Hospital, Patna according to the following criteria. This study was conducted from January 1, 2021 to June 31, 2021.

\section{Inclusion criteria}

1. Female participants who were either working or homemakers in the age group of 30-55 years and taking care of psychiatric patients diagnosed with Schizophrenia and BAPD of either sex brought to the psychiatry OPD

2. Caregiver (Mentally and physically healthy) who is a first-degree relative of the patient and staying with the patient at least for the past 2 years

3. Caregivers who give written informed valid consent.

\section{Exclusion criteria}

1. Caregivers with significant medical, neurological, and endocrinological disorders

2. Pregnant women

3. Caregivers with intellectual disability, mental illness, or substance use disorder.

\section{Sample size estimation}

Latest data from India reported moderate to severe levels of caregiver burden in $62 \%$ of the caregivers of psychiatric patients. ${ }^{6}$ Taking the effect size of $10 \%$, at $5 \%$ error and $80 \%$ power of the study, the estimated sample size is 135 using the formula:

$$
\mathrm{n}=\left(\mathrm{Z}_{\alpha / 2}+\mathrm{Z}_{\beta}\right) \times \mathrm{PQ} * 2 / \mathrm{d}^{2}
$$

were

$\mathrm{n}$ - Sample size

$Z_{\alpha / 2}-Z$ value at $5 \%$ error (1.96)

$\mathrm{P}$ is the average prevalence of the character, Q is 1-P and $\mathrm{d}$ is the effect size.

So, by rounding off, we calculated the total sample size to be 140 and formed two groups. 70 caregivers were homemakers and 70 were working women. 


\section{Study design}

Diagnosis of psychiatric illness was made as per ICD-10 criteria. A brief explanation about the study was given to the caregivers and informed consent was taken. The patients and caregivers identification data about sociodemographic status were recorded in Annexure-I and II. For assessment of caregivers' burden, their coping strategies in handling stress and impact on QOL subjects were administered "Caregiver Burden Questionnaire" (Annexure-III), "Coping Strategies Inventory" (AnnexureIV), and "WHO QoL-BREF" (Annexure-V). The study was conducted as per the good clinical practice guidelines and the declaration of Helsinki's Geneva with an approval of college ethical committee.

\section{Instruments}

1. Socio-Demographic Proforma (Annexure I and II): A Semi-structured proforma was used to obtain information about the participants and gather socio-demographic details including age, marital status, gender, educational status, economic status, history of substance use disorder, and any psychiatric illness

2. WHO QoL BREF: (Annexure V) The item scores range from 1 to 5 . Because the numbers of items are different for each domain, the domain scores are calculated by multiplying the average of the scores of all the items in the domain by the same factor of 4 . The domain scores would be having the same range starting from 4 to 20. Transformation of domain scores to a 0 -to-100-point scale was made by using the WHO-QoL transformation table. The scale has been shown to have good discriminant validity, sound content validity and good test-retest reliability at several international WHO-QoL centers. ${ }^{7}$

\section{RESULTS}

Table 1 shows the comparison of socio-demographic data of Group 1 and Group 2 caregivers. No significant difference was found between the two groups when compared in relation to age group, relation and marital status.

Table 2 shows the diagnostic classification of the psychiatric illness of patients in both the groups as per ICD 10. F20 (Schizophrenia) and F31 (BAPD) was reported among $40 \%, 60 \%$ and $41.43 \%, 58.57 \%$ of the subjects among Group 1 and Group 2, respectively. Overall, the study comprised of 57 Schizophrenic patients (40.71\%) and $83(59.29 \%)$ BAPD patients. The difference between the groups was statistically non-significant at $\mathrm{P}>0.05$.
Table 3, shows the total time spent by the caregiver on psychiatry patient amongst groups. 1-8, 9-14, >14-19 and $>19-24 \mathrm{~h}$ were spent by $25.71 \%, 57.14 \%, 12.86 \%$, $4.29 \%$ and $60 \%, 38.57 \%, 1.43 \%, 0 \%$ of the caregivers in Group 1 and Group 2, respectively. In conclusion, most of the caregivers in group 1 (57.14\%) spent 9-14 h whereas caregivers in group spent $1-8 \mathrm{~h}(60 \%)$ with statistically significant differences $\left(\chi^{2}=6.98, \mathrm{P}=0.02\right)$.

Table 4 shows the WHO-QOL comparison among Group 1 and Group 2. Mean physical, psychological, social and environmental was 12.42, 11.60, 12.24, 12.62 and $14.46,13.28,11.28,12.28$ of the caregivers in Group 1 and Group 2, respectively. When mean physical $\left(\chi^{2}=4.11\right.$, $\mathrm{P}=0.03)$, psychological $\left(\chi^{2}=3.42, \mathrm{P}=0.04\right)$ was compared among the two groups, the difference was found to be statistically significant as $\mathrm{P}<0.05$. QOL in Group 2 caregivers (Working Women) is better than Group 1 caregivers (Homemakers) in physical and psychological domains.

However, QOL in Group 1 caregivers (Homemakers) is better than Group 2 caregivers (Working Women) in social and environmental domains but statistically non-significant.

\section{DISCUSSION}

The present study was a hospital based, cross-sectional study. The total of $n=140$ caregivers were enrolled. They were further divided into two groups, Group 1 (Homemaker women) and Group 2 (Working women) of 70 caregivers each and were in the age group of 3055 years. People with mental illness (PMI) comprised of both schizophrenia and BAPD who reported to Psychiatry OPD of Government Medical College and Rajindra Hospital, Patiala accompanied by their caregivers.

In the present study, approximately $55 \%$ of the caregivers were mothers of PMI while 31\% were wives. Aggarwal et al., ${ }^{17}$ also reported similar findings. who reported majority of the caregivers to be married $76 \%$ but only $36 \%$ of PMI were taken care by their spouses. A study by Mohammed and Ghaith $(2018)^{18}$ revealed that more than two-fifths of caregivers were parents, less than one-third were son and daughter, one-fourth were spouses and only $4 \%$ of them were siblings. The higher percentages of caregivers being parents can be explained due to fact that an early onset of mental illness, which hinders with the patient prospects of an early marriage. So, parents become the natural caregivers who bring their children for treatment. The Indian societal values are such that if a person becomes mentally ill, spouses might leave him, but parents rarely abandon their children. 


\begin{tabular}{|c|c|c|c|c|c|c|}
\hline \multirow[t]{2}{*}{ Age of caregivers (in years) } & \multicolumn{2}{|c|}{ Group 1 (Homemakers) } & \multicolumn{2}{|c|}{ Group 2 (Working Women) } & \multirow[t]{2}{*}{ Chi-square } & \multirow[t]{2}{*}{ P-value } \\
\hline & $n=70$ & $\%$ & $n=70$ & $\%$ & & \\
\hline 30-35 & 14 & 20.00 & 15 & 21.43 & 1.78 & 0.21 \\
\hline $31-40$ & 8 & 11.43 & 11 & 15.71 & & \\
\hline $41-50$ & 12 & 17.14 & 24 & 34.29 & & \\
\hline $51-55$ & 36 & 51.43 & 20 & 28.57 & & \\
\hline \multicolumn{7}{|c|}{ Relationship of caregiver with Patient } \\
\hline Bhabhi & 3 & 4.29 & 4 & 5.71 & 1.46 & 0.28 \\
\hline Grandmother & 4 & 5.71 & 6 & 8.57 & & \\
\hline Mother & 41 & 58.57 & 38 & 54.29 & & \\
\hline Wife & 22 & 31.43 & 22 & 31.43 & & \\
\hline \multicolumn{7}{|l|}{ Marital status } \\
\hline Single & 0 & 0 & 0 & 0 & 0.89 & 0.67 \\
\hline Married & 70 & 100 & 61 & 87.14 & & \\
\hline Remarried & 0 & 0 & 0 & 0.00 & & \\
\hline Widowed & 0 & 0 & 8 & 11.43 & & \\
\hline Divorced & 0 & 0 & 0 & 0.00 & & \\
\hline Separated & 0 & 0 & 1 & 1.43 & & \\
\hline
\end{tabular}

Table 2: Diagnostic classification of psychiatric illnesses of patients in both the groups as per ICD-10

\begin{tabular}{|c|c|c|c|c|c|c|c|}
\hline \multirow[t]{2}{*}{ ICD 10 Diagnosis of Patients } & \multicolumn{2}{|c|}{ Group 1 (Homemakers) } & \multicolumn{2}{|c|}{ Group 2 (Working Women) } & \multirow[t]{2}{*}{ Total (\%) } & \multirow[t]{2}{*}{ Chi-square } & \multirow[t]{2}{*}{ P-value } \\
\hline & $n=70$ & $\%$ & $n=70$ & $\%$ & & & \\
\hline F20 (Schizophrenia) & 28 & 40 & 29 & 41.43 & 57 (40.71) & 0.11 & 0.82 \\
\hline F31 (BAPD) & 42 & 60 & 41 & 58.57 & 83 (59.29) & & \\
\hline
\end{tabular}

BAPD: Bipolar affective disorder

Table 3: Total time spent in caregiving by caregiver in Group 1 and Group 2

\begin{tabular}{|c|c|c|c|c|c|c|}
\hline \multirow[t]{2}{*}{ Caregivers Time Spent (in hours) } & \multicolumn{2}{|c|}{ Group 1 (Homemakers) } & \multicolumn{2}{|c|}{ Group 2 (Working Women) } & \multirow[t]{2}{*}{ Chi-square } & \multirow[t]{2}{*}{ P-value } \\
\hline & $n=70$ & $\%$ & $n=70$ & $\%$ & & \\
\hline $1-8$ & 18 & 25.71 & 42 & 60 & 6.98 & $0.02^{*}$ \\
\hline 9-14 & 40 & 57.14 & 27 & 38.57 & & \\
\hline$>14-19$ & 9 & 12.86 & 1 & 1.43 & & \\
\hline$>19-24$ & 3 & 4.29 & 0 & 0 & & \\
\hline
\end{tabular}

$\mathrm{P}<0.05$ : Significant $(*)$

\begin{tabular}{|c|c|c|c|c|c|c|}
\hline \multirow[t]{2}{*}{ Caregivers WHO-QOL } & \multicolumn{2}{|c|}{ Group 1 (Homemakers) } & \multicolumn{2}{|c|}{ Group 2 (Working Women) } & \multirow[t]{2}{*}{ t-test } & \multirow[t]{2}{*}{ P-value } \\
\hline & Mean & SD & Mean & SD & & \\
\hline Q1 & 11.27 & 2.08 & 11.86 & 2.51 & 1.72 & 0.14 \\
\hline Q2 & 11.68 & 2.43 & 11.93 & 2.58 & 1.28 & 0.32 \\
\hline Physical & 12.42 & 2.57 & 14.46 & 3.69 & 4.11 & $0.03^{*}$ \\
\hline Psychological & 11.60 & 2.40 & 13.28 & 3.25 & 3.42 & $0.04^{*}$ \\
\hline Social & 12.24 & 3.22 & 11.28 & 3.25 & 2.36 & 0.09 \\
\hline Environmental & 12.62 & 2.40 & 12.28 & 3.25 & 1.02 & 0.49 \\
\hline
\end{tabular}

Present study also revealed that $57.14 \%(n=40)$ caregivers in Group 1 spent 9-14 hours per day in care giving. However, in Group 2, 60\% spent 1-8 hours per day in caregiving. The difference in time spent in caregiving role was statistically significant among the groups. The same study founded that the amount of caring hours for patients were more than 12 hours per day for $55 \%$ of the caregivers. $58 \%$ of them were not providing care for other members of the family. $51 \%$ of the caregivers were having other persons who were helping them in caring their mentally ill patients. This high time requirement may be because of the chronic nature and severity of symptoms that characterize mental illness, which require constant care and supervision. 
In today's scenario, the husband and wife both work together to create a balance between their work life as well as at home but still it is very difficult for working women to play multiple roles of a cook, mother, wife, a nurse as well as cater to the demands of office work. So, working women can't be able to spend much time on caregiving as she has to fulfill the demands both at work and home or caregiving.

In present study, mean score physical, psychological, social and environmental quality of life domain was $12.42,11.60,12.24,12.62$ and 14.46, 13.28, 11.28, 12.28 of the caregivers in Group 1 (Homemakers) and Group 2 (Working women), respectively with statistically significant difference in the present study. So, it was observed that physical and psychological domain of QoL of Group 2 is better than Group 1. In a study by Basheer et al., (2005), ${ }^{19}$ the mean score was 15.15 in the physical domain, 12.75 in social, 12.96 in environmental and 12.52 in the psychological domain. Neong et al., $(2018)^{20}$ revealed similar results as they found that the highest mean scores for the respondents were in the physical domain, followed by social, psychological domain and environmental domain.

The Physical domain showed that our study population had good activities of daily living, energy level and mobility, less discomfort, optimal sleep and rest, and good capacity to work. The less psychological domain score in our study showed negative attitude in life and decreased self-esteem. This can be due to the social stigma associated with the mental illnesses. Our results was congruent to a previous study conducted in Taiwan. ${ }^{21}$

The negative effect of care on the caregivers' quality of life accompanies other side effects such as poor mental health, additional use of anti-depressants and increased requirement of medical and hospital care (Ayalew et al). ${ }^{22}$ Mital et al concluded that as families spend their time on caring their patients, no time is left for them to enjoy life and have recreation. frustration, stress, fear, lack of support and constant doubt were some complaints the mental patients' families stated in their quality-of-life evaluation. ${ }^{23}$

\section{Limitations of the study}

- The study is limited by the small sample size and its cross-sectional design

- The caregivers were screened for the presence of a psychiatric disorder using a clinical interview and a formal assessment was not carried out

- The psychological distress experienced by caregivers may have influenced their ratings of burden.

\section{CONCLUSION}

In physical and psychological domain of QOL, working scores were better than homemakers. QOL in working women caregivers was better than homemakers caregivers in social and environmental domains but statistically nonsignificant.

\section{ACKNOWLEDGMENT}

The authors take the opportunity to thank the Department of Psychiatry for their whole hearted support for this study.

\section{REFERENCES}

1. Gowda GS, Lepping P, Noorthoorn EO, Ali SF, Kumar CN, Raveesh BN, et al. Restraint prevalence and perceived coercion among psychiatric inpatients from South India: A prospective study. Asian J Psychiatry. 2018;36:10-16.

http://doi.org/10.1016/j.ajp.2018.05.024

2. Murthy RS. National mental health survey of India 2015-2016. Indian J Psychiatry. 2017;59(1):21-26.

https://dx.doi.org/10.4103\%2Fpsychiatry.IndianJPsychiatry_102_17

3. Sharma N, Chakrabarti S and Grover S. Gender differences in care giving among family- care givers of people with mental illnesses. World J Psychiatry. 2016;6(1):7-17.

http://doi.org/10.5498/wjp.v6.i1.7

4. Glasser M, Prohaska T and Gradval J. Elderly patients and their accompanying caregivers on medical visits. research on aging. Res Aging. 2001;23(3):326-348.

http://dx.doi.org/10.1177/0164027501233003

5. Arber $S$ and Ginn J. The meaning of informal care: Gender and the contribution of elderly people. Ageing Soc. 1990;10(4):429454. Available from: http://lawmin.nic.in/ld/P-ACT/2016/A201649.pdf [Last accessed on 2018 Jan 27].

6. Poduval $\mathrm{J}$ and Poduval $\mathrm{M}$. Working mothers: how much working, how much mothers, and where is the womanhood? Mens Sana Monogr. 2009;7(1):63-79.

https://dx.doi.org/10.4103\%2F0973-1229.41799

7. Habib RR and Zohry A. Older adults in the division of domestic labor in communities on the outskirts of Beirut. Eur J Ageing. 2006;3(3):137-45.

http://doi.org/10.1007/s10433-006-0031-3

8. Sabry WM and Vohra A. Role of Islam in the management of psychiatric disorders. Indian J Psychiatry. 2013;55(2):205-214. http://doi.org/10.4103/0019-5545.105534

9. Schulz R and Eden J. Families Caring for an Aging America. Washington, DC: United States National Academies Press; 2016. https://doi.org/10.17226/23606

10. Vlassoff C. Gender differences in determinants and consequences of health and illness. J Health Popul Nutr. 2007;25(1):47-61.

https://doi.org/10.1017/s0021932000021040

11. Yee JL and Schulz R. Gender differences in psychiatric morbidity among family caregivers: A review and analysis. Gerontologist. 2000;40(2):147-164

https://doi.org/10.1093/geront/40.2.147

12. Center for Substance Abuse Treatment. Brief Interventions and 
Brief Therapies for Substance Abuse. Rockville, MD: Substance Abuse and Mental Health Services Administration (US); 1999. (Treatment Improvement Protocol (TIP) Series, No. 34.) Chapter 7 Brief Psychodynamic Therapy; 1999.

13. Craighead EW and Nemeroff CB. The Concise Corsini Encyclopedia of Psychology and Behavioral Science The Concise Corsini Encyclopedia of Psychology. Available from: https://epdf.pub/concise-corsini-encyclopedia-ofpsychology-and-behavioral-science.html [Last accessed on 2021 Sep 07].

14. Bhui K, Dinos S, Galant-Miecznikowska M, de Jongh B and Stansfeld S. Perceptions of work stress causes and effective interventions in employees working in public, private and nongovernmental organisations: A qualitative study. BJ Psych Bull. 2016;40(6):318-325.

https://doi.org/10.1192/pb.bp. 115.050823

15. Study protocol for the World Health Organization project to develop a quality of Life assessment instrument (WHOQOL). Qual Life Res. 1993;2(2):153-159. https://apps.who.int/iris/handle/10665/51179

16. Aarti, Ruchika, Kumar R and Varghese A. Depression and quality of life in family caregivers of individuals with psychiatric illness. Int J Community Med Public Health. 2019;6(2):715-720. https://doi.org/10.18203/2394-6040.ijcmph20190196

17. Aggarwal M, Avasthi A, Kumar S and Grover S. Experience of caregiving in schizophrenia: Study from India. Int J Soc Psychiatry. 2011;57(3):224-236. https://doi.org/10.1177/0020764009352822

18. Mohammed SF and Ghaith RF. Relationship between burden, psychological well-being, and social support among caregivers of mentally ill patients. Egypt Nurs J. 2018;15(3):268-280. https://doi.org/10.4103/ENJ.ENJ_17_18

19. Basheer S, Anurag K, Garg R, Kumar R and Vashisht S. Quality of life of caregivers of mentally ill patients in a tertiary care hospital. Ind Psychiatry J. 2015;24(2):144-149. https://doi.org/10.4103/0972-6748.181721

20. Neong SC and Rashid A. Quality of life of caregivers of patients with psychiatric illness in Penang. J Clin Psychiatry Cog Psychol. 2018;2(1):12-18.

https://doi.org/10.35841/clinical-psychiatry.2.1.12-18

21. Hou SY, Ke CL, Su YC, Lung FW and Huang CJ. Exploring the burden of the primary family caregivers of schizophrenia patients in Taiwan. Psychiatry Clin Neurosci. 2008;62:508-514. https://doi.org/10.1111/j.1440-1819.2008.01843.x

22. Ayalew M, Workicho A, Tesfaye $E$, Hailesilasie $H$ and Abera $M$. Burden among caregivers of people with mental illness at Jimma University Medical, Center, Southwest Ethiopia: A crosssectional study. Ann Gen Psychiatry. 2019;18:10. https://doi.org/10.1186/s12991-019-0233-7

23. Mital AK, Sabnis SG and Kulkarni VV. Caregiver burden in medical versus psychiatric patients: A cross-sectional comparative study. Indian J Psychol Med. 2017;39(6):777-784. https://doi.org/10.4103/IJPSYM.IJPSYM_335_17

\section{Authors' Contributions:}

VPS- Concept and design of the study; prepared first draft of manuscript; AP, EG-Interpretation of results, literature review and manuscript preparation;

APS, NPS- Concept, coordination, review of literature and manuscript preparation; NPS- Statistical analysis and interpretation, manuscript preparation and revision of manuscript. All authors approved the final version of the manuscript.

Work attributed to:

Patna Medical College and Hospital, Patna, Bihar, India

ORCID ID:

Dr. Vivek Pratap Singh- (10 https://orcid.org/0000-0002-6780-2484

Dr. Alka Puria- (1) https://orcid.org/0000-0001-9513-9635

Dr. Abhishek Pratap Singh- (i) https://orcid.org/0000-0003-1893-0305

Dr. Ekram Goyal- (i) https://orcid.org/0000-0001-8389-6284

Dr. Narendra Pratap Singh- (1) https://orcid.org/0000-0002-6997-5311

Source of Funding: None, Conflict of Interest: None. 